\title{
MODELING OF PROFESSIONAL FOREIGN LANGUAGE COMMUNICATION (BY THE EXAMPLE OF AGROBUSINESS AREA)
}

\author{
Zhyltyrova Zhanar Tekesbaikyzy \\ Ms., Kazakh Ablai Khan University of International Relations and World Languages, Kazakhstan, \\ zhanar.tekesbaikyzy@mail.ru
}

\begin{abstract}
The paper is aimed to discuss the notion of model and modeling in training professional foreign language the students majoring in agrarian domain. As the foreign language education has to be focused on the development of communication skills and be directed towards the profession in working out the curriculum of any major, it is necessary to develop the speaking skills for professional communication in the field of (English for Specific Purposes) ESP training. Therefore the professionally-oriented tasks develop students' language skills and they are the simplest way of getting learners involved into the future professional process via realizing the modeling of professionally-oriented situations. Analysis and literature review of scholars studying model, its types, features and application in communication were discussed in the paper. Taking into account the approach as being a learning strategy and the general direction in learning a foreign language, it should be mentioned in dealing with modeling. So some modeling approaches as system, competence-based and cognitive-communicative were also presented in the work. The content of professional foreign language education is also mentioned which is considered to be one of the most important components in competence-based approach of educational process. The content of foreign language education is studied in two aspects: subject and processual. The characteristic feature of the subject content is a cognitive-linguocultural complex. The processual aspect consists of communicative tasks, exercises and problems, collection of typical situations, case-studies, creative essays and etc. Every aspect with a practical example of modeling professional foreign language communication is described in the paper.
\end{abstract}

Keywords: modeling, model, foreign language training, professional foreign language communication.

\section{INTRODUCTION}

In modern realities specialists' foreign language proficiency becomes an essential factor in the development of professional competence, which significantly increases the demand on the labor market.

Over the last 4 years training of future specialists in the higher educational system of Kazakhstan is addressed to the professional communication in Kazakh, Russian and Foreign languages (English 
language). Within the framework of discipline "Professionally-oriented Kazakh language", "Professionallyoriented Russian language" and "Professionally-oriented Foreign language" students learn the language material, including a special vocabulary, grammar related to an official-business and scientific styles of speech, mastering oral and written communication used in professional-business sphere, themes and situations of professional business communication. Foreign language education has to be focused on communication skills and be directed towards the profession in the curriculum of any major. In order to meet the requirements of the society, it is necessary to develop the speaking skills for professional communication in the field of ESP training. Therefore this paper is aimed to discuss an attempt to implement a model of professional foreign language communication in training students of Agrobusiness area.

\section{MAIN PART}

Modeling is a scientific activity, the aim of which is to make a particular part or feature of the world easier to understand, define, quantify, visualize or simulate by referencing it to existing and usually commonly accepted knowledge.

Modeling refers to the process of constructing and studying models. Shtoff V.A. determines model as "a display facility, reproducing a particular part of reality, with the aim of learning more in-depth from observations and experiments to various forms of theoretical generalizations (Shtoff, 1966, pp. 22).

Definition of a model includes four features:

1. Model is a mentally represented or materially realized system;

2. Model reflects the object of study;

3. Model is able to replace the object;

4. The study of a model provides new information on a subject (Kraevskii, 1998, pp. 180).

In other way round we can say that model is an artificially created object in the form of diagrams, symbolic formulas, which, being similar to the object under study shows and reproduces structure, properties, relationships between the elements of the object in a simple and summarized form.

Friedman L.I. revealed the following types of models: material (physical) and ideal (mental images of objects and the relations between them) (Friedman, 1984, pp 29-35). The operation of ideal models is carried out by the means of language (language tools). In this case words and sentences serve as the real objects, actions and relations replacement.

Grunig J. and Hunt T. suggested models of communication in the field of public relations which could be also suitable for methodology of teaching languages:

- Press Agentry Model- this method is usually employed by practitioners for one way communications;

- Public Information Model - this model does not consider information about the audience to be essential in constructing messages and releases;

- Two Way Asymmetric Model - the goal of this model is to get into the psychology of their audience so that messages can be tailored to get the most effective reaction;

- Two Way Symmetric Model - this is probably the most ethical method of all the models. The aim of this model is a dialogue not monologue. It attempts to find a mutually advantageous solution to a problem (Grunig and Hunt, 2014). From the abovementioned models it can be seen that some models are one-sided and it is obviously clear the communication should be two-sided like a Symmetric Model.

In the Methodology as well as in General Didactics the method of modeling is widely used for studying pedagogical processes that are connected with speaking skills acquiring. The scientists occupied with modeling always underline that the models in all cases act as analogues of the objects of study, i.e. they are similar to the latter, but are not identical to them.

With the help of constructed models one can a) illustrate a particular area of knowledge; b) study the process of speaking skills and abilities development; c) monitor the learners' process of the language and speaking abilities development. The models, from their part, permit one to define what knowledge there should be, what characteristic speaking skills and abilities being formed should have (Bezukladnikov, Shamov and Novoselov, 2013, pp. 903-910).

Research has revealed that model constructing of professional foreign language communication should be connected with approaches. The choice of approaches is a rather complicated problem, which in relation 
with each other can make the methodological basis for modeling. A set of concepts, ideas, methods and techniques used in the process of cognition and transformation of the educational activity depends on determining a methodological approach.

In pedagogical literature, the term "approach" is used as a set of ideas and methods underlying problem solving. The approach in foreign language learning process is defined as a learning strategy and the general direction in learning a foreign language (Kunanbayeva, 2013, pp.99).

If we separately describe each approach, first of all, it is obvious to mention about the system approach. The system approach is a rational, problem solving method of analyzing and making the educational process more effective. A system is a set of elements that function as a whole to achieve a common purpose (Siddiqui, 2013). System approach in education means that the separate components of the pedagogical system are considered in correlation with the other elements as learning objectives, whereas teachers and students are considered as subjects of the educational process, methods, forms and means of teaching process. Changing one of the components entails a change in all the others and the system collapses. In order to set the system, it is necessary not only to identify its structural elements, but also to identify a set of connections between them, that is, to describe how the components of the model are interdependent.

The next cognitive-communicative approach is presented by Bezukladnikov K.E. Training foreign language lexis requires the whole pedagogical process modeling of the lexical level units' assimilation. According to the considered approach the process of the professional vocabulary mastering appears as a cognitive system (structure). Cognitive system is a component of a person's consciousness (mind), his/her general cognition. Student's cognitive activity while learning the words of a language is very difficult to observe. That's why for this purpose the model is created (Bezukladnikov, Shamov and Novoselov, 2013, pp. 903910).

Taking into account that the priority goal of educational process is the formation of competences, it is necessary to emphasize the role of competence-based approach. Competence-based approach seeks to teach language in relation to the context. Language always occurs as a medium of interaction and communication between people for achieving specific goals and purposes. Defining competence-based approach Baidenko V.I. supposes that a student acquires knowledge, skills in a complex, wherein the purpose of learning is considered to be more close to the situations of professional sphere. Also, this approach, being focused on the objectives and assessment of academic results, it has its own demands to the other components of the educational process as content, teaching techniques, methods, monitoring and evaluation (Baidenko, 2004).

According to Kunanbayeva S.S. the content of professional foreign language education is based on the cognitive-linguocultural methodology and the modelling of foreign language education competence, as modelled educational process focuses on the final (competence) result close to the conditions of real communication (Kunanbayeva, 2013, pp.99).

Kunanbayeva S.S. considers the content of foreign language education in two aspects: subject and processual. Subject content considers thematic-textual units in communicative spheres and communicative topics. The characteristic feature of the subject content is a cognitive-linguocultural complex (CLC). Cognitive-linguocultural complex is an educational material which includes communicative complex, communicative spheres, thematic-textual units and situations that enable student to feel himself/herself in two linguocultural spaces (Kunanbayeva, 2013, pp.99).

The processual aspect consists of communicative tasks, exercises and problems, collection of typical situations, case-studies, creative essays and etc. which is provided by the co-called communicative complex (CC). Communicative complex (CC) is a system for managing the development of communicative skills and competences within the parameters of particular spheres of communication. Therefore the organizational basis of the subject aspect of the content is allocated under communicative spheres. In accordance to Khaleeva I.I. communication being a feature of everyday life should be organized in 4 communicative spheres and they are as follows:

a. Professional-productive;

b. Social-domestic;

c. Social-cultural;

d. Social-political (Khaleeva, 1990, pp. 20).

Professional foreign language communication is realized in three main stages: 
a. the preparatory stage of communication;

b. the stage of modeling the typical communicative situations;

C. the stage of professional communication (Kunanbayeva, 2013, pp.99).

Every stage introduces various types of exercises that leads to the professional communication and develops a set of professional intercultural competences. The preparatory stage of familiarization with all meta-units relating to the theme of a content are organized through reading texts which provide information about professional area.

Modeling of professional foreign language allows using properly the teaching materials. The following example-model could be taken for training students of non-English majoring university in Agrarian area.

Sphere of communication - Professional-productive;

Theme of communication - Agrobusiness;

Sub-topics:

- Agrarian economy of the Republic of Kazakhstan;

- The prospects of development the agriculture and etc.

\section{The first is the preparatory stage of communication.}

1. Exercises on the conceptual and cognitive step.

1.1 Sample exercise-control on understanding the objects, concepts, definitions reproduction in given contexts.

- What is an agrarian economy?

- What is the difference between overall economy and agrarian one?

- How do you understand the business economy of an agricultural sector?

1.2 Students are given a text-definition "Agrobusiness" for reading on the conceptual and cognitive step

2. The next exercise is for the assessment and critical processing of information. This type of exercise can be realized by watching some video materials or by listening to recordings connected with the topic of a lesson wherein subsequently students express their point of view on the received material.

\section{The second stage is modeling typical situations and variations.}

Students read and listen to a sample dialogue in order to be familiarized. After it using the model-dialogue, they can make similar conversation in accordance to the situation.

\section{The last stage is a professional communication.}

This stage of communication can be implemented via discussions, dialogues and debates where students solve some professional issues and tasks in English language.

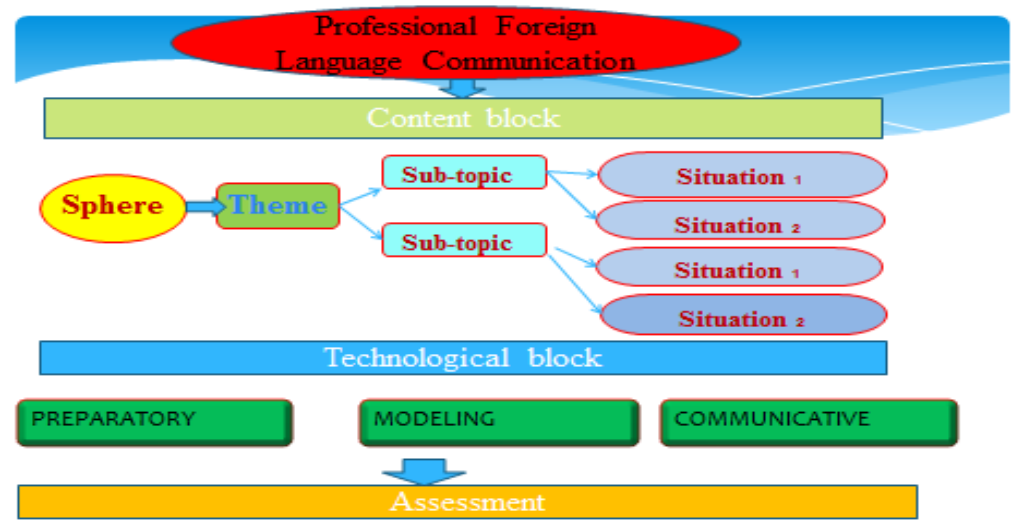

Fig. 1. The model of professional foreign language communication 
Example of situation for conversation.

A private entrepreneur deals with milk production and he is looking for company- dealers in order to export dairy products. Discuss with your partner about the prospects of this business and mention about difficulties which can occur. Define your roles.

The measurement is assessed by qualitative and quantitative indicators. Following this idea, extra attention should be paid to the issue of developing assessment.

This model of professional foreign language communication helps us to clarify, understand the professional concept, terminology, lexical elements and hereinafter develop the ability to use them in speech.

\section{CONCLUSION}

The analysis of modeling phenomenon, its approaches and application in foreign language education as an effective means for training students were described in the paper. In conditions of modern globalization, where the situation of a dialogue is crucial in international relations, situational use of foreign language presupposed and determined certain professional sphere. On the basis of offered stages in realizing communication, students were able to understand the concept, terminology and thoughts that were contained in the professionally-oriented exercises and texts for listening and reading. The speaking area under discussion enhanced students' speaking skills in a professional field and motivated them to acquire foreign language which leads them to be competent graduates ready to act effectively and responsibly in multilingual and multi-cultural environments.

\section{REFERENCE LIST}

Baidenko, V.I. (2004). Competences in professional education. Higher education in Russia.

Bezukladnikov, K.E., Shamov, A.N. and Novoselov, M.N. (2013). Modeling of Educational Process Aimed at Forming Foreign Language Professional Lexical Competence. World Applied Sciences Journal 22 (7).

Grunig, J. and Hunt T., https://www.linkedin.com/pulse/20140611205435-83891954-the-four-models-ingrunig-s-and-hunt-s-pr-theories

Friedman, L.I. (1984). Visibility of modeling in training. Moscow, Knowledge.

Khaleeva, I.I. (1990). The theoretic basics of learning to understand foreign speech. Moscow.

Kunanbayeva, S.S. (2013). The Modernization of Foreign Language Education: The LinguoculturalCommunicative Approach. United Kingdom: Hertfordshire Press.

Kraevskii, V.V. (1998). Problems of scientific foundation in learning. Moscow-Riga.

Shtoff, V.A. (1966). Modelling in philosophy.

Siddiqui, M.H. (2013). http://www.worldwidejournals.com/indian-journal-of-applied-research(IJAR)/file.php?val=February $2013 \quad 1359812023 \quad 55158$ 29.pdf 